\title{
Endoscopic bronchial valve treatment: patient selection and special considerations
}

\author{
This article was published in the following Dove Press journal: \\ International Journal of COPD \\ 8 October 2015 \\ Number of times this article has been viewed
}

\author{
Ralf Eberhardt ${ }^{1,2}$ \\ Daniela Gompelmann ${ }^{1,2}$ \\ Felix JF Herth ${ }^{1,2}$ \\ Maren Schuhmann' \\ 'Pneumology and Critical \\ Care Medicine, Thoraxklinik at \\ the University of Heidelberg, \\ ${ }^{2}$ Translational Lung Research Center, \\ Member of the German Center for \\ Lung Research, Heidelberg, Germany
}

\begin{abstract}
As well as lung volume reduction surgery, different minimally invasive endoscopic techniques are available to achieve lung volume reduction in patients with severe emphysema and significant hyperinflation. Lung function parameters and comorbidities of the patient, as well as the extent and distribution of the emphysema are factors to be considered when choosing the patient and the intervention. Endoscopic bronchial valve placement with complete occlusion of one lobe in patients with heterogeneous emphysema is the preferred technique because of its reversibility. The presence of high interlobar collateral ventilation will hinder successful treatment; therefore, endoscopic coil placement, polymeric lung volume reduction, or bronchoscopic thermal vapor ablation as well as lung volume reduction surgery can be used for treating patients with incomplete fissures. The effect of endoscopic lung volume reduction in patients with a homogeneous distribution of emphysema is still unclear and this subgroup should be treated only in clinical trials. Precise patient selection is necessary for interventions and to improve the outcome and reduce the risk and possible complications. Therefore, the patients should be discussed in a multidisciplinary approach prior to determining the most appropriate treatment for lung volume reduction.
\end{abstract}

Keywords: lung emphysema, valve treatment, collateral ventilation, patient selection, outcome

\section{Introduction}

COPD is a common disease with a worldwide increasing incidence because of the smoking behavior of the population. ${ }^{1,2}$ Sixty-five million people worldwide suffer from COPD, which is associated with high morbidity and rising mortality. In 2005, 3 million people died of this chronic disease and it is estimated that COPD will become the third leading cause of death by $2020 .{ }^{3,4}$

COPD, however, is not a disease but rather a syndrome with various phenotypes depending on which clinical symptoms and pathophysiological aspects are predominant. Productive cough, shortness of breath, and limited exercise capacity are the main symptoms of the disease, significantly reducing the quality of life in the advanced stages of COPD. Pathophysiologically, the symptoms are explained by chronic bronchitis with mucus hypersecretion, irreversible bronchoconstriction with expiratory airflow limitation, as well as emphysematous destruction of lung parenchyma associated with hyperinflation and impaired respiratory mechanics as a result of inflammation. ${ }^{2}$ Early in the course of the disease, an increase in the residual volume (RV) as an expression of progressive hyperinflation can be observed..$^{5}$ A raised respiratory rate during or after exertion leads to dyspnea because of the dynamic hyperinflation with an increase in the end-expiratory lung volume. Therapeutic interventions, therefore, have to aim at reducing hyperinflation with an improvement in lung function and dyspnea. ${ }^{6}$
Correspondence: Ralf Eberhardt Pneumology and Critical Care Medicine, Thoraxklinik at the University of Heidelberg, Amalienstrasse 5, D-69126 Heidelberg, Germany Email ralf.eberhardt@med.uniheidelberg.de 


\section{Treatment for COPD}

COPD is a chronic and progressive disease with no curative treatment approach except lung transplantation, which may be considered in a minority of select patients with advanced COPD. Therefore, the principal aim of therapy is to prevent the progression of the disease and reduce disease-induced mortality. As defined in the international COPD guidelines by the Global initiative for chronic Obstructive Lung Disease smoking cessation, disease-adapted exercise, and pulmonary rehabilitation as well as influenza and pneumococcal vaccinations are the most important therapeutic strategies. ${ }^{2}$ Pharmacological therapy of COPD includes bronchodilatation ( $\beta 2$-agonists and anticholinergic agents), topical corticosteroids, and oral phosphodiesterase inhibitors depending on the severity of dyspnea, bronchoconstriction, and the frequency of exacerbations. Long-term oxygen therapy is recommended in patients with chronic respiratory failure. Ventilatory support is indicated in patients with significant hypercapnia and related clinical symptoms.

\section{Lung volume reduction surgery}

In a selected subgroup of patients with emphysematous destruction of lung tissue followed by severe static and dynamic hyperinflation, lung volume reduction can be a further treatment option. Minimizing hyperinflation increases lung elastic recoil, improves the shape of the diaphragm, and optimizes respiratory mechanics with the reduction in the work of breathing. ${ }^{7}$

Lung volume reduction surgery (LVRS) has been shown to effectively address these physiological abnormalities with improvements in symptoms, lung function, exercise tolerance, and survival in selected patients with advanced emphysema. ${ }^{8,9}$ The largest study of LVRS, the National Emphysema Treatment Trial (NETT), suggested that patients with an upper-lobe predominant pattern of disease benefit the most from LVRS. ${ }^{10}$ On the other hand, an increased postoperative mortality after 90 days $(7.9 \%)$ was observed in the surgically treated group. A multivariate analysis indicated that a forced expiratory volume in 1 second $\left(\mathrm{FEV}_{1}\right) \leq 20 \%$ predicted plus a very low diffusion capacity (DLCO $\leq 20 \%$ predicted) and/or a homogeneous distribution of emphysema was independently predictive of 90-day mortality. Therefore, these patients have been identified as high-risk patients for LVRS, ${ }^{11}$ although the findings of the NETT have not been universally replicated. ${ }^{12}$ Even though LVRS is recommended for end-stage severe emphysema patients, numbers have declined in the USA since the publication of NETT. ${ }^{13}$ These findings, however, led to the development of less invasive endoscopic techniques for lung volume reduction to mimic the effects of LVRS.

\section{Endoscopic lung volume reduction}

In the past decade, different approaches for endoscopic lung volume reduction (ELVR) have been developed. These techniques differ in indication, mechanism of action, reversibility, as well as complications and are divided into two groups: blocking and nonblocking devices. These methods have been approved in Europe, but not by the US Food and Drug Administration to date.

The nonblocking approaches include endoscopic coil implantation (lung volume reduction coil [LVRC]; PneumRx, Inc., Mountain View, CA, USA), polymeric lung volume reduction with air sealant (PLVR; Aeris Therapeutics, Inc., Woburn, MA, USA), and bronchoscopic thermal vapor ablation (BTVA; Uptake Medical, Corp., Tustin, CA, USA). In the first technique, nitinol coils are bronchoscopically delivered straight into the desired subsegmental bronchus, returning to their predetermined coil shape upon deployment. This approach results in volume reduction by retracting the airways and compressing the diseased lung parenchyma. It is hypothesized that the implanted coils retension the surrounding tissue, which may increase elastic recoil and redirect air to healthier portions of the lung. ${ }^{14}$ At this time, LVRC is approved for upper- and lower-lobe treatment and can be used in heterogeneous as well as homogeneous predominant emphysema. ${ }^{15,16}$ The exact mechanism of action is not clear, however, and needs further evaluation.

Both PLVR and BTVA work on an alveolar level and lead to an inflammatory reaction in the lung periphery, followed by tissue scarring of the treated lobe resulting in a significant volume reduction. ${ }^{17,18}$ Only treatment of the upper lobes is currently suggested for both techniques. However, because of an excessive inflammatory response in a few cases, the use of BTVA is recommended only in clinical trials and in a stepwise manner. ${ }^{19}$ Because of the lack of sponsors, PLVR is currently not available.

Common to all of the nonblocking ELVR methods is the nonreversibility and the independence of the presence of collateral ventilation $(\mathrm{CV}) .^{20-22}$

\section{Endoscopic bronchial valve placement}

The most frequent and best-studied bronchoscopic technique for treating emphysema to date is endobronchial valve (EBV) therapy. It represents the blocking technique of ELVR modalities in which the most emphysematous destroyed lobe is occluded by one-way valves. ${ }^{23}$ These valves allow the air 

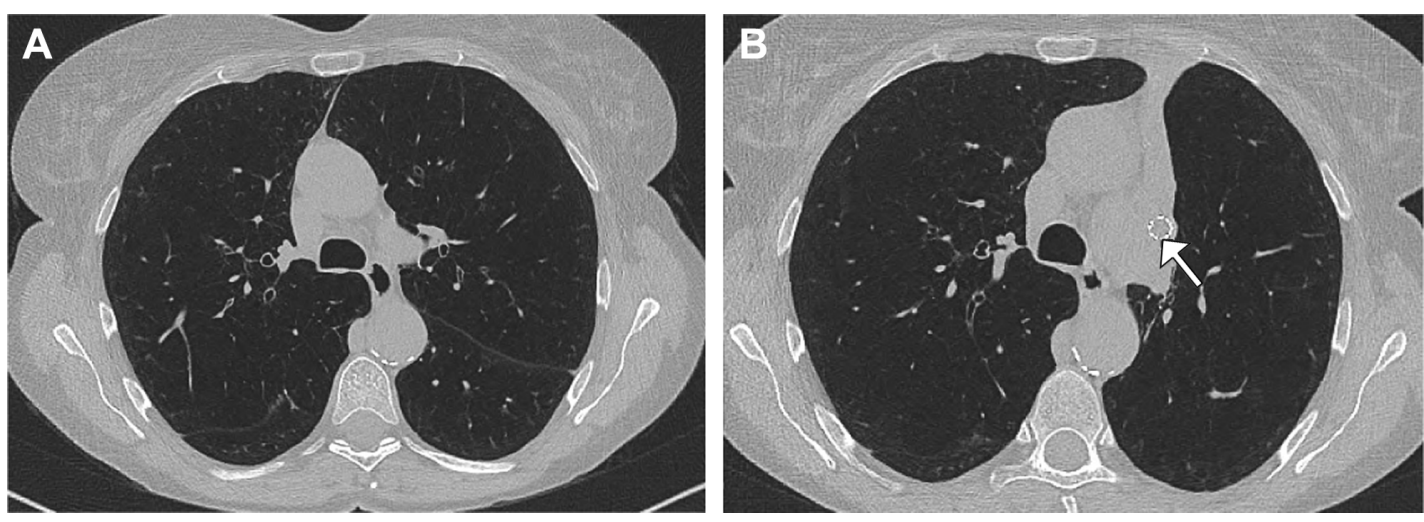

Figure I High-resolution computed tomography prior to $(\mathbf{A})$ and after $(\mathbf{B})$ endoscopic valve placement leading to a complete atelectasis in the left upper lobe. The arrow shows an implanted endobronchial valve.

to exit during expiration, but stop it from entering during inspiration. Therefore, a volume reduction in the occluded lobe, ideally a complete lobar atelectasis as the maximum result following valve therapy, can be achieved (Figure 1).

Two different types of valves - EBV (Zephyr ${ }^{\circledR}$, Pulmonx Corp., Redwood City, CA, USA) and intrabronchial valves (IBV, Spiration ${ }^{\circledR}$, Olympus, Tokyo, Japan) - are available, and they differ in shape but have a similar mechanism of action (Figure 2). The choice between one of the two types is influenced more by the bronchial anatomy rather than by different outcomes after valve placement. Although no comparative trial has been published, the effect of both types of valves seems to be similar.

In 2003, the first experiences of endoscopic EBV implantation in patients with severe emphysema were published. ${ }^{24,25}$ The first randomized controlled trial, the Endobronchial
Valve for Emphysema Palliation Trial (VENT), evaluated the effect of additional EBV placement to medical therapy including pulmonary rehabilitation in heterogeneous emphysema. ${ }^{26}$ In this trial, 214 patients with advanced emphysema were treated by a complete occlusion of the targeted lobe (upper or lower lobe) by EBV and compared to 101 patients who received standard medical care only. The patients treated with EBV developed an improvement in $\mathrm{FEV}_{1}$ of $4.3 \%(+34.5 \mathrm{~mL})$, whereas the patients in the control group experienced a decrease of $2.5 \%(-25.4 \mathrm{~mL})$. Similar results were observed in the 6-minute-walk test (6-MWT: $+9.3 \mathrm{~m}$ vs $-10.7 \mathrm{~m}$, respectively), health-related quality of life measured by St George's Respiratory Questionnaire (SGRQ -2.8 points vs +0.6 points), and modified Medical Research Council dyspnea scale ( -0.1 points vs +0.2 points). Although the mean between-group difference

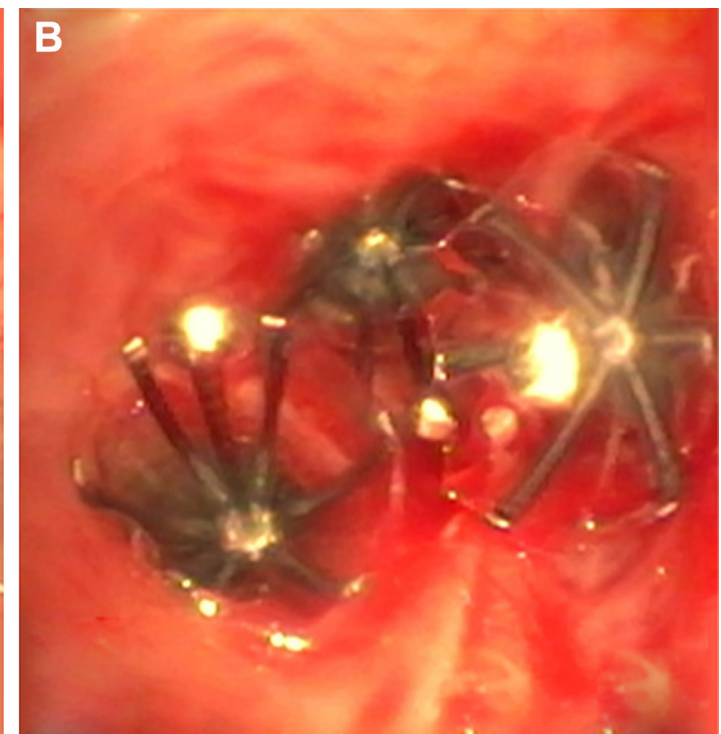

Figure 2 Different types of bronchial valves.

Notes: (A and B) Right - endobronchial valves (Zephyr ${ }^{\circledR}$, Redwood City, CA, USA) have been placed in the left lower lobe. Left - intrabronchial valves in the left upper lobe (Spiration ${ }^{\circledR}$, Olympus, Tokyo, Japan). 
was significant, the results were not clinically relevant. The significant improvements after EBV treatment, however, were confirmed in the European cohort of the VENT (EuroVENT) trial following the same study protocol. ${ }^{27}$

In a pilot trial for ELVR using IBV an improvement in the health-related quality of life SGRQ was shown, but not in pulmonary function $\left(\mathrm{FEV}_{1}\right)$ or exercise capacity (6-MWT). In this trial, a bilateral treatment with incomplete occlusion of the target lobes in patients with upper-lobe predominant emphysema was preferred to avoid a postinterventional pneumothorax. In two subsequent randomized controlled trials, with bilateral incomplete IBV treatment, no significant and/or clinically meaningful differences could be observed between the intervention group and the control group. ${ }^{28,29}$

In a retrospective analysis, the direct correlation between the amount of target lobe volume reduction (TLVR) and the outcome was shown. ${ }^{30}$ Patients who achieved a TLVR of $>50 \%$ after unilateral EBV treatment improved in $\mathrm{FEV}_{1}$ by $+26 \%$, in $6-$ MWT by $+19 \mathrm{~m}$, and in SGRQ by -6.2 points whereas patients with a volume reduction in the treated lobe of $<20 \%$ did not show any improvement, similar to the control group without valve treatment. Hence, for a better outcome following valve placement, complete and successful occlusion of the treated lobe and a subsequent high TLVR is needed. Another randomized trial using IBV confirmed that single lobe complete occlusion is superior to a bilateral partial treatment. Currently, a complete lobar occlusion of a single lobe is recommended even in bilateral emphysema patients. ${ }^{31}$

\section{Patient selection}

As described, different surgical and/or endoscopic techniques for interventional treatment of patients with advanced emphysema and severe hyperinflation are available. The less invasive methods of ELVR can be very effective in subgroups of emphysema patients, in turn leading to substantial improvements in lung function, dyspnea, exercise capacity, and finally in the quality of life. There are first indications that patients even have a survival benefit after successful endoscopic valve therapy. ${ }^{32,33}$ Overall, however, the published evidence for these new treatments is low. For this reason, some uncertainty exists as to the indication and the selection of the correct patients.

To improve the outcome of the different techniques and to choose the best treatment option, dedicated screening, and selection of potential candidates is necessary. Not every patient with advanced COPD or severe emphysema is, in principle, suitable for ELVR intervention. In order to select the best patients, elementary knowledge about the different techniques and their indications as well as their possible complications is considered a prerequisite for successful interventional emphysema therapy (Figure 3).

\section{Pulmonary function and exercise capacity testing}

Lung volume reduction is a treatment option for symptomatic COPD patients with advanced emphysema having shortness of breath and low exercise tolerance despite maximal medical therapy. The inclusion and exclusion criteria for most of the clinical trials for ELVR have been copied from the surgical NETT. ${ }^{10}$ Therefore, patients with an $\mathrm{FEV}_{1}$ of $<45 \%$ predicted and both an RV of $>150 \%$ predicted and a total lung capacity of $>100 \%$ were enrolled. Owing to the postoperative excess mortality reported in the NETT in the high-risk group, patients with a DLCO of $<20 \%$ have usually been excluded from the trials.

In contrast, according to expert opinion, patients with an $\mathrm{FEV}_{1}$ of $<35 \%$ predicted and an RV of more than $200 \%$ tend to benefit more from an intervention, although this reflects the clinical experience rather than the published evidence. Even patients with a DLCO of $<20 \%$ predicted can be treated because the reduced DLCO is only a surgical predictor for postoperative mortality. ${ }^{11}$ The lower the DLCO, the greater the emphysematous destruction of the lungs and during patient selection both the overall periinterventional risk and the functional reserve of the patient for complications should be considered. However, it should be observed that a not insignificant number of patients are unable to perform a DLCO assessment correctly because of the inability to breath-hold for up to 10 seconds. Therefore, the value of this test for patient selection must be questioned and, today, a DLCO of $<20 \%$ predicted is not a strict contraindication for bronchial valve placement in our hospital.

A 6-minute walk distance (6-MWD) of $>140 \mathrm{~m}$ represents a parameter for better endurance and for the functional reserve of the patient. ${ }^{10}$ Both the 6-MWD and the requirement of pulmonary rehabilitation prior to interventional emphysema treatment are surgical inclusion criteria to minimize the peri- and postoperative morbidity, and their relevance in the less invasive procedures for ELVR is unclear. Patients might possibly benefit more from a pulmonary rehabilitation program after ELVR, because the training conditions will be improved as a result of a better pulmonary function and higher endurance, without increased risk for peri-interventional complications. 


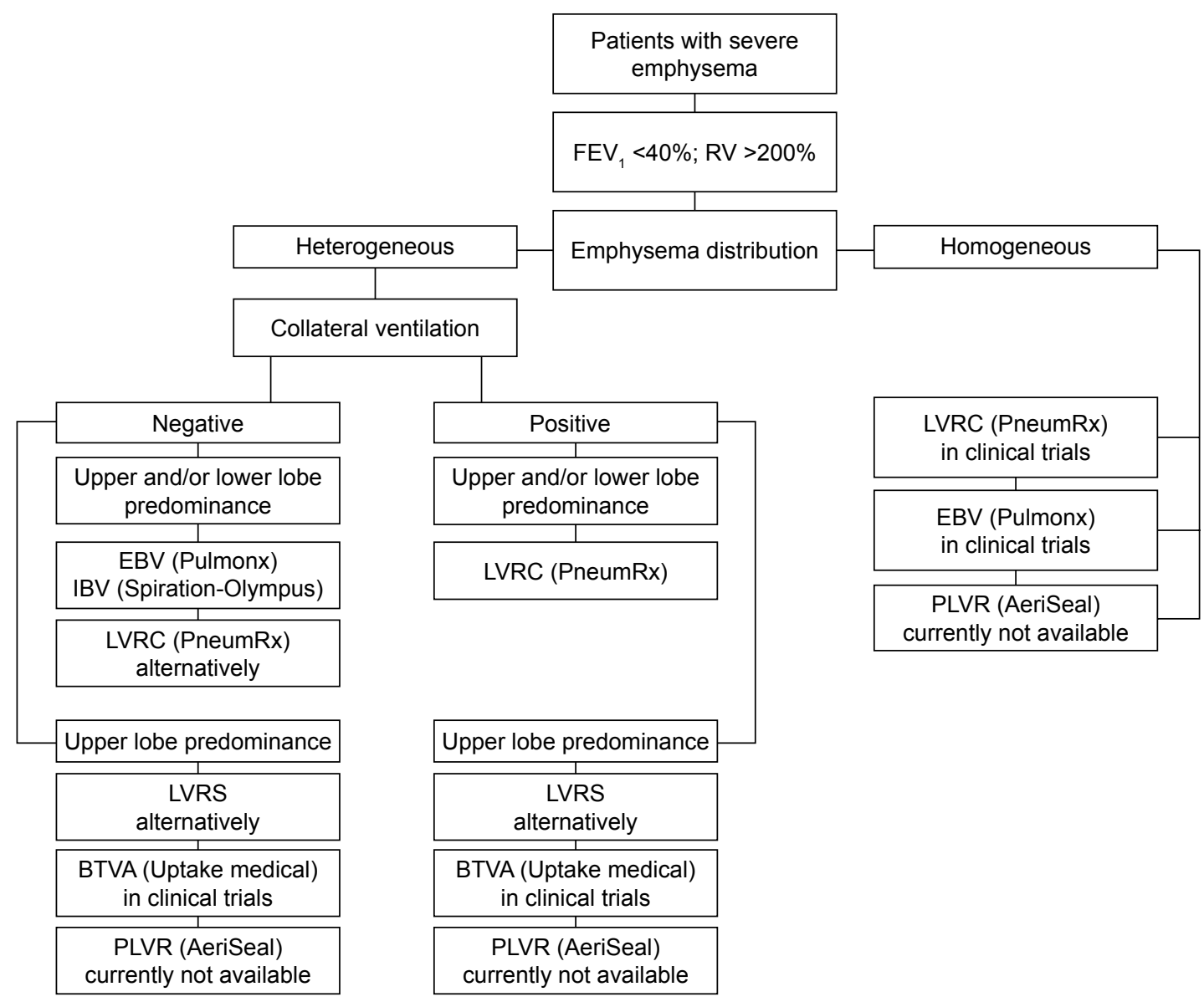

Figure 3 Recommended algorithm for patient selection depending on emphysema distribution as well as on the presence or absence of collateral ventilation. Abbreviations: FEV, forced expiratory volume in I second; RV, residual volume; EBV, endobronchial valve; IBV, intrabronchial valve; LVRC, lung volume reduction coil; LVRS, lung volume reduction surgery; BTVA, bronchoscopic thermal vapor ablation; PLVR, polymeric lung volume reduction.

\section{High resolution computed tomography}

High-resolution computed tomography (HRCT) is, in addition to the pulmonary function testing, an absolute prerequisite for adequate patient selection. Normally used in a low-dose protocol with a slice thickness of $\leq 1 \mathrm{~mm}$, the HRCT enables the detection and quantification of the destruction of the peripheral lung tissue. Automated software programs help to visualize the severity and distribution of emphysema. ${ }^{34}$

According to the results of the NETT, interventional endoscopic treatments are also commonly limited to patients with severe heterogeneous emphysema. Depending on the predominance, bronchial valve placement is possible in the upper lobes as well as in the lower lobes. In VENT and EuroVENT the outcome was similar for both, without an increased risk for either of the group. ${ }^{26,27}$ Currently, the most treated lobe by bronchial valves in our hospital, a high-volume center for surgical and ELVR, is the left lower lobe.

Nitinol coils (LVRC) can also be used for both upper and lower predominant emphysema patients. Owing to the missing evidence for nonupper-lobe treatment, PLVR and BTVA are currently only recommended for use in upper-lobe predominant emphysema, although it may also be beneficial in lower-lobe predominant emphysema and further trials are needed.

Patients with a homogeneous distribution of their emphysema did not show a benefit after LVRS ${ }^{10}$ and therefore patients with homogeneous emphysema were mostly excluded from endoscopic trials. It is estimated that patients with homogeneous emphysema may have a higher degree of $\mathrm{CV}$ between the ipsilateral lobes and consequently will not benefit from an endoscopic valve placement. ${ }^{35} \mathrm{~A}$ small case series showed that even patients with a homogeneous distribution could benefit with regard to the quality of life, although the number of patients is too small to detect improvements in $\mathrm{FEV}_{1}$ or 6-MWD. ${ }^{36}$ Currently, patients with severe homogeneous emphysema are being recruited into a European multicenter trial (IMPACT NCT02025205) to evaluate the effect of EBV placement in this patient subgroup. 
The first uncontrolled studies show the feasibility and a positive, though reduced, effect of LVRC and PLVR treatment in patients with homogeneous emphysema. ${ }^{16,17}$ In contrast, BTVA shows a better outcome in patients with a greater heterogeneity, therefore in the latest trial for bronchial vapor ablation, only patients with high heterogeneity of emphysema between the ipsilateral lobes have been included.

Finally, COPD patients with severe airways obstruction, but a low degree of emphysematous destruction of their lung tissue, seem to be unsuitable candidates for either a surgical and/or ELVR procedure.

\section{Collateral ventilation and fissure analysis}

Although the VENT showed only significant, but not clinically relevant improvements for the patients treated with EBV, a post hoc subgroup analysis demonstrated that patients with a complete interlobar fissure in the preinterventional HRCT experienced excellent outcomes following valve implantation. ${ }^{26}$ A complete fissure is currently defined as being $>90 \%$ complete between the target and adjacent lobes in at least one axis on the computed tomography (CT) scan (Figure 4). A complete fissure seems to be a surrogate indicator for low interlobar $\mathrm{CV}$, whereas the detection of large parenchymal connections is associated with a significant air exchange independent of the central airways. Therefore, patients with an incomplete fissure will not benefit from valve treatment, as the occluded lobe can be backfilled through the collateral channels. This finding was confirmed by the results of the Euro-VENT ${ }^{27}$ In this randomized trial, 111 patients with emphysema underwent valve placement and were compared with 60 patients who were treated by standard medical care. Patients with a complete interlobar fissure and a successful occlusion of the targeted lobe by

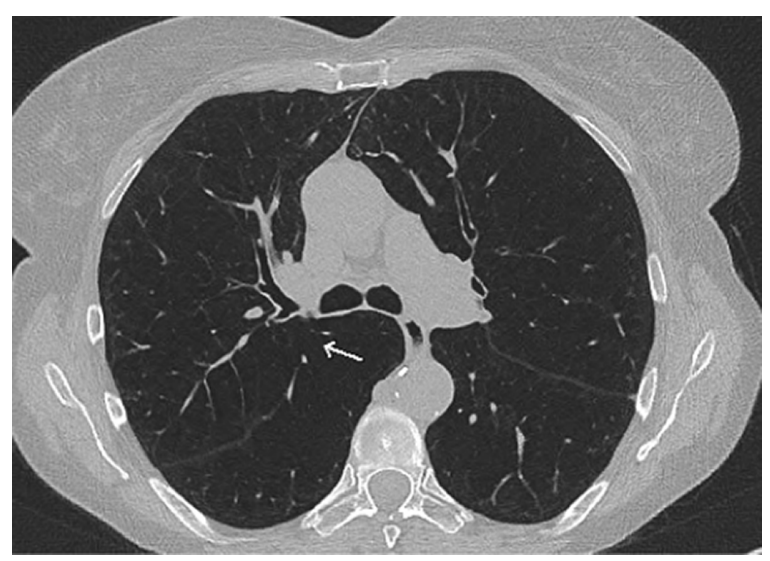

Figure 4 High-resolution computed tomography of a patient with severe emphysema showing an incomplete fissure $(\uparrow)$ on the right and a complete fissure on the left.
EBV developed a mean lobar volume reduction of $80 \%$ associated with an improvement in $\mathrm{FEV}_{1}$ of $+26 \%$ and in 6-MWT of $+22 \mathrm{~m}$, whereas patients with an incomplete fissure showed no improvement after valve placement similar to the control group.

Besides CT based fissure analysis, CV can be quantified by an invasive catheter-based measurement using the Chartis ${ }^{\circledR}$ Pulmonary Assessment System (Pulmonx Corp.). A dedicated catheter with an inflatable balloon at the distal tip can be advanced via the working channel of a standard bronchoscope and inserted into the targeted lobe. After isolating the lung compartment by inflating the balloon, the airflow and the airway pressure are measured and thus $\mathrm{CV}$ can be quantified ${ }^{37}$ (Figure 5). Patients with no significant interlobar ventilation who will benefit from valve implantation are classified as "CV negative", and patients with a high interlobar flow are classified as "CV positive" who are not candidates for valve therapy. In a prospective multicenter trial the accuracy of $\mathrm{CV}$ assessment using the Chartis ${ }^{\circledR}$ System prior to valve placement was evaluated..$^{38}$ Eighty patients with severe heterogeneous emphysema and indication for valve therapy underwent $\mathrm{CV}$ measurements followed by EBV placement. In this trial, 36 of 51 patients, who were classified as CV negative, responded as predicted with a significant TLVR, whereas 24 of the 29 $\mathrm{CV}$ positive patients experienced only insignificant volume reduction. Overall, the accuracy of the Chartis ${ }^{\circledR}$ System for correctly predicting TLVR was found to be $75 \%$. Another retrospective trial that compared the $\mathrm{CT}$ fissure analysis with catheter-based CV measurement demonstrated that both techniques are comparable and present efficient methods to optimize patient selection for valve treatment. ${ }^{39}$

\section{Quantitative CT analysis and perfusion scan}

Although clinically routine visual analysis of the fissure integrity can be performed with a good degree of confidence in CT images, experienced readers might be required for a more reliable assessment. Analyzing the fissures in three different dimensions visually can be a challenge and special training and skills of the radiologists are needed. ${ }^{40,41}$ Today, automated software solutions are available for quantifying the fissure integrity (Figure 6A). Using the raw data and a threshold of -910 to -950 Hounsfield units (HU), the distribution and the severity of the destruction of the peripheral lung tissue can be assessed and the emphysema can be quantified automatically or semi-automated. The heterogeneity index is defined as the difference in emphysema score between the target lobe and adjacent lobe. A value of $>15 \%$ 


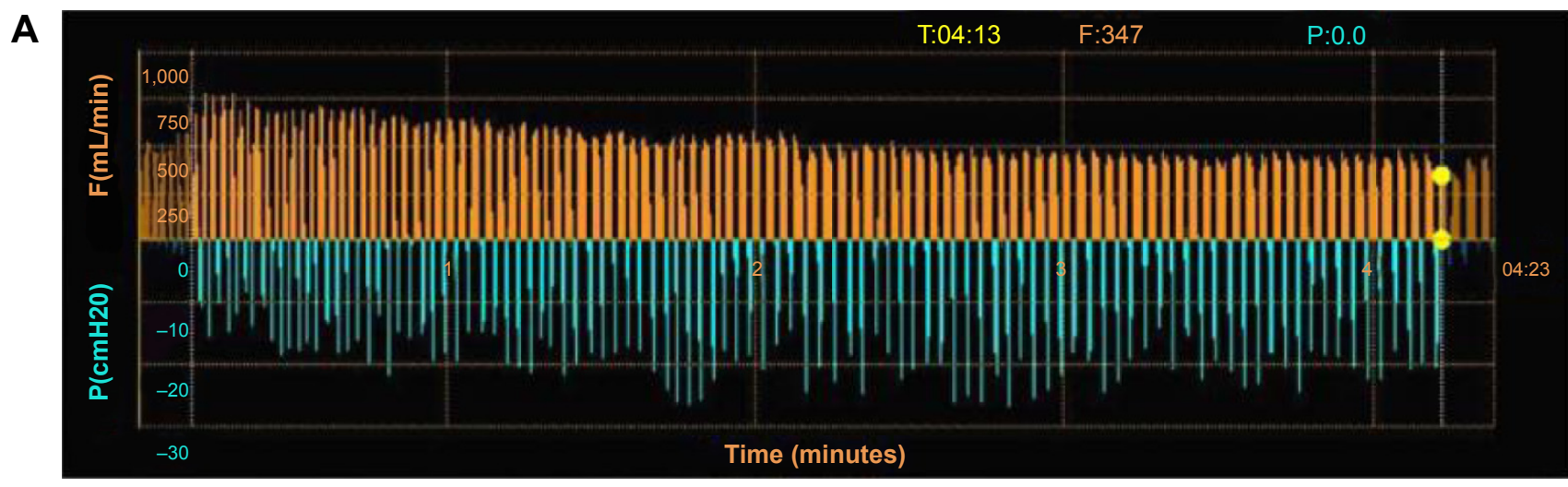

B

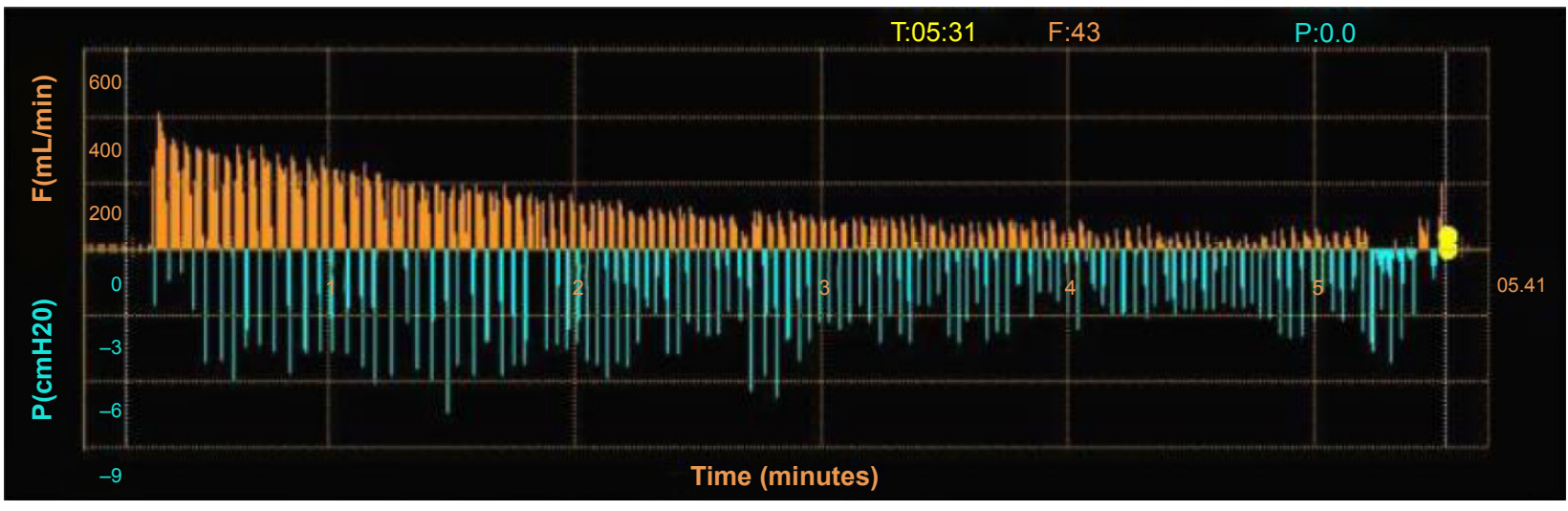

Figure 5 Assessment of collateral ventilation using Chartis system (Pulmonx Corp., Redwood City, CA, USA).

Notes: (A) No reduction in flow $\mathrm{F}(\mathrm{mL} / \mathrm{min})$; orange lines visualized indicating presence of collateral ventilation and incomplete fissure in the right upper lobe. The blue lines show the changes in intralobar pressure $\mathrm{P}(\mathrm{cmH} 20)$ during spontaneous respiration. (B) A reduction in flow (orange lines) can be seen in the left upper lobe over a time period of more than 5 minutes, while the breathing effort (blue lines) does not change. This indicates no collateral ventilation and complete fissure in the left lung making valve placement possible.

Abbreviations: $\mathrm{P}$, pressure; F, flow.

A

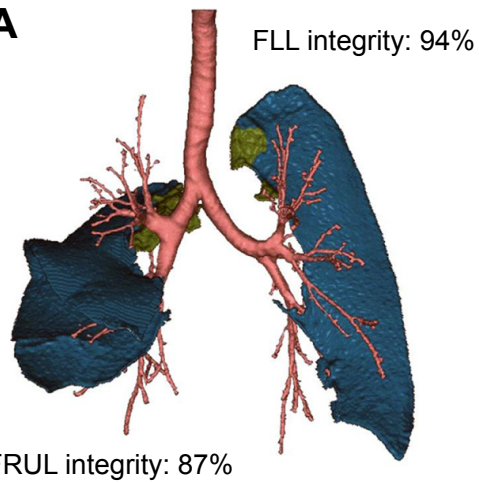

B

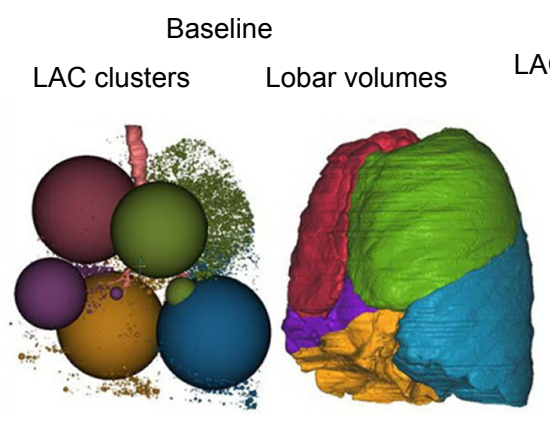

Follow-up 1 month

AC clusters Lobar volumes

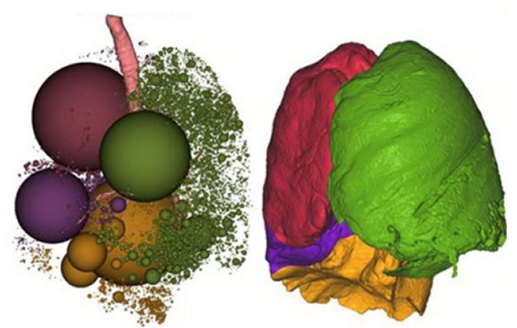

Figure 6 Automated software analysis for fissure integrity and emphysema severity and distribution using Apollo ${ }^{\mathrm{TM}}$ software (Vida Diagnostics, Inc., Minneapolis, MN, USA).

Notes: (A) Fissure analysis showing in blue fissure integrity of the right upper lobe of $87 \%$ and on the left of $94 \%$. The green areas represent small fissure defects. (B) Lung volume responder with predominant lower lobe disease. The low attenuation cluster (LAC) map is a representation of the overall distribution of emphysema in the different lobes (RUL, red; RML, purple; RLL, yellow; LUL, green; LLL, blue). Each sphere is the aggregate of connected low attenuation areas defined by using the -950 HU threshold, and its size is proportional to the size of connected low density areas. The surface rendering representation provides a visual indication of the lobar volume reduction effect of the treatment, in particular for the target and ipsilateral lobes. Emphysema percentage in the LLL as expressed by the low attenuation area percentage was LAA\%-950 $=53.7 \%$, with a heterogeneity score of $15.4 \%$. The follow-up scan I month after the endobronchial valve therapy of the left lower lobe shows a complete atelectasis of the treated lobe (reduction in lobar volume of $2,120.1 \mathrm{~cm}^{3}$ ) and an expansion of the ipsilateral lobe.

Abbreviations: FLL, fissure left lung; FRUL, fissure right upper lobe; LLL, left lower lobe; LUL, left upper lobe; RLL, right lower lobe; RML, right middle lobe; RUL, right upper lobe. 
is deemed to be heterogeneous whereas a value of $\leq 15 \%$ is homogeneous. A calculated emphysema score as well as the heterogeneity index can be used not only for patient selection but also to assess these patients after an intervention. ${ }^{34}$ However, the thresholds are not standardized yet and applying different software programs can lead to different results. ${ }^{42}$ Furthermore, these programs offer the physicians additional parameters such as peripheral pulmonary vessel volume and low attenuation clusters (LACs), which have been shown to also play a role in predicting outcomes. ${ }^{43}$

Peripheral pulmonary vessel volume represents the percentage of small vessels of the segmented patient vessel tree. With increasing emphysema, the vascular tree becomes sparser, vessels are squeezed and the contribution of the smallest segmented vessels increases in percentage relative to the overall vasculature. LAC is an index of terminal airspace enlargement and emphysema severity using a threshold of $-950 \mathrm{HU}$, which can discriminate low attenuation areas from gas trapping, imaging noise, and emphysema. LAC has been shown to correlate with the visual extent of emphysema $^{43}$ (Figure 6B).

Other approaches such as CT-based specific gas volume measurements to identify areas of emphysematous obstruction are still in their early stages but might improve patient selection for lung volume reduction in the future. ${ }^{44}$ Fissure completeness, however, remains the most important predictor for success as a surrogate indicator for the presence or absence of high $\mathrm{CV} .{ }^{27}$

In emphysematous destroyed lung parenchyma, the perfusion is reduced by the Euler-Liljestrand mechanism. A perfusion scan can therefore be useful to confirm the target zone for lung volume reduction and to verify heterogeneity. In a retrospective analysis, patients with a low target lobe regional perfusion had a significant improvement in 6-MWD when compared with those with a high baseline target lobe regional perfusion $(30.2$ vs $3.7 \mathrm{~m}) .{ }^{45}$ Patients with a low perfusion in the target lobe at baseline benefited from bronchial valve placement, independent of the degree of target lobe destruction on CT scan. Although perfusion scanning is not consistently used worldwide, a perfusion scan prior to treatment is recommended by the authors to enhance the clinical outcome of emphysema patients undergoing lung volume reduction. Magnetic resonance imaging may in future be used to evaluate the perfusion of the lung. ${ }^{46}$

\section{Comorbidities and other considerations}

Numerous comorbidities are responsible for the exclusion of patients from endoscopic valve therapy. It is also important to note that interventional emphysema therapy is not suited for an emergency treatment during acute exacerbation or respiratory failure, but rather for patients in a stable disease phase.

Comorbidities such as bronchiectasis, repeated infections of the lower airways and frequent exacerbations of COPD, as well as a greater amount of sputum and bronchial secretions are unfavorable and are contraindications for ELVR in these patients. Patients with chronic respiratory failure and severe hypercapnia, pulmonary hypertension, as well as alpha 1-antitrypsin deficiency have mostly been excluded from clinical trials for ELVR. However, a small case series showed that EBV placement is feasible in patients with mild to moderate pulmonary hypertension and that reduction in the hyperinflation can lead to improvements in both pulmonary and cardiac functions. ${ }^{47}$

Even patients with lower lobe predominant emphysema secondary to alpha 1-antitrypsin deficiency can benefit from an endoscopic valve treatment, ${ }^{48}$ whereas no data have been published for patients with significant hypercapnia and ELVR. In theory, an improvement in the respiratory mechanics after lung volume reduction should be followed by a reduction in the work of breathing and a decrease in hypercapnia. However, initiating noninvasive ventilation prior to treatment can be helpful in these selected cases to manage possible postinterventional respiratory failure.

To date, patients who continue to smoke have been excluded from clinical trials for lung volume reduction. The health benefits of smoking cessation are generally known; therefore, patients who are still smoking should undergo smoking cessation therapy prior to evaluating them for any interventional emphysema therapy.

\section{Complications}

Although all endoscopic techniques for lung volume reduction are classified as minimal invasive procedures, possible complications need to be taken into consideration. A simple bronchoscopy may lead to a postprocedural worsening of the airway obstruction. In the VENT COPD exacerbations (9.3\%), hemoptysis (6.1\%), valve migration (4.7\%), and pneumothorax $(4.2 \%)$ have been reported as the most common adverse events following valve therapy. ${ }^{26}$ Although these are typical complications after valve placement, the incidence is much lower than initially expected. Even entirely occluding a bronchus with a valve, infection, and poststenotic pneumonia is only rarely observed. Hemoptysis is only mild because of the invasive procedure and usually self-limiting, whereas valve migration can be seen if the size of the valve has been wrongly selected. 
The most important complication observed is a pneumothorax because of its relatively high frequency and its potential life-threatening risk in the case of a tension pneumothorax. ${ }^{49}$ The incidence of pneumothorax has increased markedly over the last few years and it is currently reported at $23 \% .{ }^{50}$ The reason for the rising incidence is the improved patient selection focusing more on $\mathrm{CV}$ negative patients. A complete interlobar fissure is a predictor for both excellent outcome following valve therapy and postinterventional pneumothorax. Patients who develop a pneumothorax as a complication following valve implantation, however, will nevertheless benefit from valve treatment. In a retrospective trial of patients with pneumothorax after ELVR, a mean TLVR of $65 \%$ was observed. ${ }^{49}$ Pneumothorax can be a serious complication associated with prolonged hospitalization and the need for further interventions (chest tube insertion and video-assisted thoracoscopy), and in particular a tension pneumothorax is a life-threatening complication. Therefore, strict monitoring of patients within the first 48-72 hours following intervention is crucial as pneumothorax develops within the first 3 days $^{50}$ in $76.6 \%$ of cases. The management of this complication can be an interdisciplinary challenge and a dedicated algorithm on how to treat a pneumothorax after valve placement was published. ${ }^{51}$

For LVRC, a postinterventional pneumothorax has also been described, but its occurrence is less frequent. A typical complication after coil implantation can be mild-to-moderate airway bleeding. Therefore, patients with the need for sustained anticoagulation should not be treated with this technique. For PLVR and BTVA, the major complication is an excessive inflammatory response with the risk of pneumonitis and respiratory failure.

\section{Conclusion}

ELVR is a new treatment option for patients with advanced COPD and severe emphysema. Nevertheless, medical therapy, pulmonary rehabilitation, as well as smoking cessation remain the basis of therapy. Patients who are potential candidates for ELVR should have a reduced $\mathrm{FEV}_{1}(<40 \%$ predicted) and severe hyperinflation ( $\mathrm{RV}>200 \%$ predicted), but comorbidities need to be taken into consideration as well.

In comparison to LVRS, the endoscopic procedures are less invasive alternatives with the opportunity to improve shortness of breath, exercise capacity, and quality of life in the patients, who have reached the end of their conventional treatment options.

Different interventional approaches are available nowadays, of which the endoscopic bronchial valve placement presents the most frequently used method. A common feature of all these procedures is their applicability in patients with heterogeneous emphysema. While valves and coils can be used for lung volume reduction in both upper- and lower-lobe emphysema, PLVR and BTVA are reserved for patients with upper-lobe predominant emphysema. Patients with homogeneous emphysema may also benefit from ELVR, but because of the low amount of evidence available, they should only be treated in clinical trials.

For proper patient selection, the emphysema severity and distribution have to be assessed by high resolution CT, ideally in combination with an automated software analysis. The most important predictor of success in endoscopic valve placement is low interlobar $\mathrm{CV}$ or rather a completeness of the fissures. Therefore, patients with high $\mathrm{CV}$, measured endoscopically, or with radiologically proven incomplete fissures, should not be treated with valves. Although other techniques for ELVR are independent of $\mathrm{CV}$, in patients who have a low interlobar flow, bronchial valve placement should be preferred because of its reversibility. Other techniques can be an alternative after valve removal, when there is valve dysfunction or no clinical improvement.

It is important to note that LVRS has been shown to be effective for emphysema treatment and may be the first choice in some patients with more bullous or paraseptal emphysema. Therefore, patients who are being considered for lung volume reduction should be discussed in an interdisciplinary setting.

\section{Acknowledgments}

The authors gratefully acknowledge Professor CP Heussel at the Thoraxklinik, University of Heidelberg, for the CT images and also VIDA Diagnostics, Inc., Minneapolis, MN, USA, for the images of the Apollo Software ${ }^{\mathrm{TM}}$ analysis.

\section{Disclosure}

All authors have previously been investigators in different clinical trials for ELVR. FJFH has provided consulting services for Pulmonx Corp., USA. RE, DG, and MS have received funding for educational activities from Pulmonx Corp. and Olympus Europa, Inc/Germany. The authors report no other conflicts of interest in this work.

\section{References}

1. Murray CJ, Lopez AD. Measuring the global burden of disease. $N$ Engl $J$ Med. 2013;369(5):448-457.

2. Vestbo J, Hurd SS, Agusti AG, et al. Global strategy for the diagnosis, management, and prevention of chronic obstructive pulmonary disease: GOLD executive summary. Am J Respir Crit Care Med. 2013;187(4) $347-365$. 
3. World Health Organisation. Burden of COPD. Available from: http:// www.who.int/respiratory/copd/burden/en/

4. Gillissen A. Herausforderungen, Zukunftsperspektiven, Forschungsansätze. Zur Lage und Zukunft der Pneumologie in Deutschland. Weißbuch Lunge 2014. Herne: FRISCHETEXTE Verlag; 2014. German.

5. O'Donnell DE. Hyperinflation, dyspnea, and exercise intolerance in chronic obstructive pulmonary disease. Proc Am Thorac Soc. 2006;3(2):180-184.

6. Macklem PT. Therapeutic implications of the pathophysiology of COPD. Eur Respir J. 2010;35(3):676-680.

7. Fessler HE, Scharf SM, Ingenito EP, McKenna RJ Jr, Sharafkhaneh A. Physiologic basis for improved pulmonary function after lung volume reduction. Proc Am Thorac Soc. 2008;5(4):416-420.

8. Gelb AF, Zamel N, McKenna RJ Jr, Brenner M. Mechanism of shortterm improvement in lung function after emphysema resection. Am J Respir Crit Care Med. 1996;154(4 Pt 1):945-951.

9. Gelb AF, McKenna RJ Jr, Brenner M, Fischel R, Baydur A, Zamel N. Contribution of lung and chest wall mechanics following emphysema resection. Chest. 1996;110(1):11-17.

10. Fishman A, Martinez F, Naunheim K, et al. A randomized trial comparing lung-volume-reduction surgery with medical therapy for severe emphysema. N Engl J Med. 2003;348(21):2059-2073.

11. Naunheim KS, Wood DE, Krasna MJ, et al. Predictors of operative mortality and cardiopulmonary morbidity in the National Emphysema Treatment Trial. J Thorac Cardiovasc Surg. 2006;131(1):43-53.

12. Weder W, Tutic M, Lardinois D, et al. Persistent benefit from lung volume reduction surgery in patients with homogeneous emphysema. Ann Thorac Surg. 2009;87(1):229-236; discussion 236-227.

13. Berger RL, Decamp MM, Criner GJ, Celli BR. Lung volume reduction therapies for advanced emphysema: an update. Chest. 2010;138(2): $407-417$.

14. Kontogianni K, Gerovasili V, Gompelmann D, et al. Effectiveness of endobronchial coil treatment for lung volume reduction in patients with severe heterogeneous emphysema and bilateral incomplete fissures: a six-month follow-up. Respiration. 2014;88(1):52-60.

15. Slebos DJ, Klooster K, Ernst A, Herth FJ, Kerstjens HA. Bronchoscopic lung volume reduction coil treatment of patients with severe heterogeneous emphysema. Chest. 2012;142(3):574-582.

16. Klooster K, Ten Hacken NH, Franz I, Kerstjens HA, van Rikxoort EM, Slebos DJ. Lung volume reduction coil treatment in chronic obstructive pulmonary disease patients with homogeneous emphysema: a prospective feasibility trial. Respiration. 2014;88(2):116-125.

17. Herth FJ, Gompelmann D, Stanzel F, et al. Treatment of advanced emphysema with emphysematous lung sealant (AeriSeal(R)). Respiration. 2011;82(1):36-45.

18. Snell G, Herth FJ, Hopkins P, et al. Bronchoscopic thermal vapour ablation therapy in the management of heterogeneous emphysema. Eur Respir J. 2012;39(6):1326-1333.

19. Valipour A, Herth FJ, Eberhardt R, et al. Design of the randomized, controlled sequential staged treatment of emphysema with upper lobe predominance (STEP-UP) study. BMC Pulm Med. 2014;14:190.

20. Magnussen H, Kramer MR, Kirsten AM, et al. Effect of fissure integrity on lung volume reduction using a polymer sealant in advanced emphysema. Thorax. 2012;67(4):302-308.

21. Gompelmann D, Heussel CP, Eberhardt R, et al. Efficacy of bronchoscopic thermal vapor ablation and lobar fissure completeness in patients with heterogeneous emphysema. Respiration. 2012;83(5): 400-406.

22. Deslee G, Klooster K, Hetzel M, et al. Lung volume reduction coil treatment for patients with severe emphysema: a European multicentre trial. Thorax. 2014;69(11):980-986.

23. Gompelmann D, Eberhardt R, Herth FJ. Endoscopic lung volume reduction. A European perspective. Ann Am Thorac Soc. 2013;10(6): 657-666.

24. Toma TP, Hopkinson NS, Hillier J, et al. Bronchoscopic volume reduction with valve implants in patients with severe emphysema. Lancet. 2003;361(9361):931-933.
25. Snell GI, Holsworth L, Borrill ZL, et al. The potential for bronchoscopic lung volume reduction using bronchial prostheses: a pilot study. Chest. 2003;124(3):1073-1080.

26. Sciurba FC, Ernst A, Herth FJ, et al. A randomized study of endobronchial valves for advanced emphysema. $N$ Engl J Med. 2010;363(13): 1233-1244.

27. Herth FJ, Noppen M, Valipour A, et al. Efficacy predictors of lung volume reduction with Zephyr valves in a European cohort. Eur Respir J. 2012;39(6):1334-1342.

28. Ninane V, Geltner C, Bezzi M, et al. Multicentre European study for the treatment of advanced emphysema with bronchial valves. Eur Respir J. 2012;39(6):1319-1325.

29. Wood DE, Nader DA, Springmeyer SC, et al. The IBV Valve trial: a multicenter, randomized, double-blind trial of endobronchial therapy for severe emphysema. J Bronchology Interv Pulmonol. 2014;21(4): 288-297.

30. Valipour A, Herth FJ, Burghuber OC, et al. Target lobe volume reduction and COPD outcome measures after endobronchial valve therapy. Eur Respir J. 2014;43(2):387-396.

31. Eberhardt R, Gompelmann D, Schuhmann M, Heussel CP, Herth FJ. Complete unilateral vs partial bilateral endoscopic lung volume reduction in patients with bilateral lung emphysema. Chest. 2012;142(4): 900-908.

32. Hopkinson NS, Kemp SV, Toma TP, et al. Atelectasis and survival after bronchoscopic lung volume reduction for COPD. Eur Respir J. 2011;37(6):1346-1351.

33. Venuta F, Anile M, Diso D, et al. Long-term follow-up after bronchoscopic lung volume reduction in patients with emphysema. Eur Respir J. 2012;39(5):1084-1089.

34. Heussel CP, Herth FJ, Kappes J, et al. Fully automatic quantitative assessment of emphysema in computed tomography: comparison with pulmonary function testing and normal values. Eur Radiol. 2009;19(10): 2391-2402.

35. Higuchi T, Reed A, Oto T, et al. Relation of interlobar collaterals to radiological heterogeneity in severe emphysema. Thorax. 2006;61(5): 409-413.

36. Eberhardt R, Heussel CP, Kreuter M, Weinheimer O, Herth FJ. Bronchoscopic lung volume reduction in patients with severe homogeneous lung emphysema: a pilot study. Dtsch Med Wochenschr. 2009;134(11): 506-510.

37. Gompelmann D, Eberhardt R, Michaud G, Ernst A, Herth FJ. Predicting atelectasis by assessment of collateral ventilation prior to endobronchial lung volume reduction: a feasibility study. Respiration. 2010;80(5): 419-425.

38. Herth FJ, Eberhardt R, Gompelmann D, et al. Radiological and clinical outcomes of using Chartis to plan endobronchial valve treatment. Eur Respir J. 2013;41(2):302-308.

39. Gompelmann D, Ralf E, Slebos DJ, et al. Comparison between Chartis ${ }^{\mathbb{R}}$ pulmonary assessment system detection of collateral ventilation vs corelab CT fissure analysis in predicting atelectasis in emphysema patients treated with endobronchial valves. Abstract presented at: ERS Annual Congress; 2012; Vienna, Austria.

40. Koenigkam-Santos M, de Paula WD, Owsijewitsch M, et al. Incomplete pulmonary fissures evaluated by volumetric thin-section CT: semiquantitative evaluation for small fissure gaps identification, description of prevalence and severity of fissural defects. Eur J Radiol. 2013;82(12): 2365-2370.

41. Koenigkam-Santos M, Puderbach M, Gompelmann D, et al. Incomplete fissures in severe emphysematous patients evaluated with MDCT: incidence and interobserver agreement among radiologists and pneumologists. Eur J Radiol. 2012;81(12):4161-4166.

42. Heussel CP, Achenbach T, Buschsieweke C, et al. Quantification of pulmonary emphysema in multislice-CT using different software tools. Rofo. 2006;178(10):987-998.

43. Schuhmann M, Raffy P, Yin Y, et al. Computed tomography predictors of response to endobronchial valve lung reduction treatment. Comparison with chartis. Am J Respir Crit Care Med. 2015;191(7):767-774. 
44. Aliverti A, Pennati F, Salito C, Woods JC. Regional lung function and heterogeneity of specific gas volume in healthy and emphysematous subjects. Eur Respir J. 2013;41(5):1179-1188.

45. Argula RG, Strange C, Ramakrishnan V, Goldin J. Baseline regional perfusion impacts exercise response to endobronchial valve therapy in advanced pulmonary emphysema. Chest. 2013;144(5):1578-1586.

46. Biederer J, Heussel CP, Puderbach M, Wielpuetz MO. Functional magnetic resonance imaging of the lung. Semin Respir Crit Care Med. 2014;35(1):74-82.

47. Eberhardt R, Gerovasili V, Kontogianni K, et al. Endoscopic lung volume reduction with endobronchial valves in patients with severe emphysema and established pulmonary hypertension. Respiration. 2015; 89(1):41-48.
48. Hillerdal G, Mindus S. One- to four-year follow-up of endobronchial lung volume reduction in alpha-1-antitrypsin deficiency patients: a case series. Respiration. 2014;88(4):320-328.

49. Gompelmann D, Herth FJ, Slebos DJ, et al. Pneumothorax following endobronchial valve therapy and its impact on clinical outcomes in severe emphysema. Respiration. 2014;87(6):485-491.

50. Gompelmann D, Herth FJF, Heussel CP, Hoffmann H, Dienemann H, Eberhardt R. Pneumothorax nach endoskopischer Ventiltherapie. Pneumologie. 2014;68:V454.

51. Valipour A, Slebos DJ, de Oliveira HG, et al. Expert statement: pneumothorax associated with endoscopic valve therapy for emphysemapotential mechanisms, treatment algorithm, and case examples. Respiration. 2014;87(6):513-521.

\section{Publish your work in this journal}

The International Journal of COPD is an international, peer-reviewed journal of therapeutics and pharmacology focusing on concise rapid reporting of clinical studies and reviews in COPD. Special focus is given to the pathophysiological processes underlying the disease, intervention programs, patient focused education, and self management protocols.

\section{Dovepress}

This journal is indexed on PubMed Central, MedLine and CAS. The manuscript management system is completely online and includes a very quick and fair peer-review system, which is all easy to use. Visit http://www.dovepress.com/testimonials.php to read real quotes from published authors.

Submit your manuscript here: http://www.dovepress.com/international-journal-of-chronic-obstructive-pulmonary-disease-journal 